\title{
CPW Fed Koch Modified Fractal Antenna Backed with Partial Ground for Multiband Wireless Applications
}

\author{
Rajib Kumar DASH ${ }^{1}$, Puspendu Bikash SAHA ${ }^{1}$, Dibyendu GHOSHAL ${ }^{1}$, Gopinath PALAI ${ }^{2}$ \\ ${ }^{1}$ Dept. of Electronics and Communication Engineering, National Institute of Technology, Agartala, 799046, India \\ ${ }^{2}$ Dept. of Electronics and Communication Engineering, Gandhi Institute for Technological Advancement, \\ Bhubaneswar, 752054, India
}

rkdashece@gmail.com, bikashsuccess@gmail.com, tukumw@gmail.com,gpalai28@gmail.com

Submitted August 18, 2020 / Accepted March 16, 2021

\begin{abstract}
In this article, modified Koch fractal geometrybased patch antenna up to second iteration is implemented with partial ground configuration to achieve multiband response with wideband behavior at each of the resonating bands. The antenna is designed to operate over $C$ and $X$ bands that can be useful for Satellite, Radar and DBS TV applications. FR-4 epoxy substrate of maximum dimension $35 \times 30 \times 1.6 \mathrm{~mm}^{3}\left(0.70 \lambda_{0} \times 0.6 \lambda_{0} \times 0.03 \lambda_{0}\right)$ is used to simulate the antenna in HFSS $15\left(\lambda_{0}\right.$ is the free space wavelength corresponding to the lowest resonance frequency). The design is started with a truncated star shape patch and ended up with five circular slots embedded Koch fractal through several design steps. In addition, coplanar waveguide $(C P W)$ feeding is applied to achieve multiband response and wideband behavior over each operating band. The proposed antenna exhibits multiband response at $6.06 \mathrm{GHz}, 9.76 \mathrm{GHz}, 10.92 \mathrm{GHz}, 11.68 \mathrm{GHz}$ and $14.4 \mathrm{GHz}$ with operating bands $(5.8-6.31 \mathrm{GHz}),(9.2-10.08 \mathrm{GHz})$, $(10.78-12.36 \mathrm{GHz})$ and $(13.64-15 \mathrm{GHz})$ respectively. A fabricated prototype of the proposed antenna is tested using Vector Network Analyzer (VNA). It has shown adequate amount of matching between the simulation and measured results.
\end{abstract}

\section{Keywords}

CPW feeding, modified Koch fractal, multiband, partial ground, truncated patch, wideband

\section{Introduction}

In recent trend of wireless technologies, demands of multiband and wideband antennas are increasing to meet the requirement of using a single antenna for multiple frequency bands instead of using multiple antennas. Wideband antennas are very useful in multipath channel where data rate with low interference and less transmission power is required. Multiband antennas are required to use the frequency spectrum efficiently. Different slots along with fractal curve have been used in literature like circular slots
[1], reverse C-shaped and L-shaped slot [2], plus shaped slots [8], triangular slots [12], fractal slots [13], [14] etc. to achieve multiband characteristics. Apart from slots different fractal shaped curves like crinkle fractal [5], I-shaped [6], circular ring fractal [7], [9], meander like fractal [10], dual reverse arrow fractal [11], modified Sierpinski gasket fractal [11], Minkowski fractal [15], Sierpinski fractal [16], [17], periwinkle flower shaped fractal [19] and hybrid fractal [20-22] also have been used to get multiband response. Alongside multiband response efforts have also been given to enhance bandwidth using several techniques like partial ground $[3,20,23]$, crinkle fractal with partial ground [5], ring fractal with partial ground [8], circular slotted hexagonal shaped ring [10], elevated slotted triangular patch [11], fractal slot based DGS [13], [21] and Minkowski fractal with triangular dielectric resonator [15] in multiband antennas. CPW plates along with ground plane [3] are used to improve performance like gain and bandwidth over the operating frequency bands and CPW feeding has also been applied to achieve multiband response [19]. Simple microstrip patch antenna designed with different shaped slots at different position resulted multiband response [1], [2]. A CPW fed antenna loaded with partial ground plane is designed to improve bandwidth in each resonating band [3]. Improvement in bandwidth with single band response and reduction of cross polarization using Z-shaped slot loaded ground plane is discussed in [4]. The application of fractal geometry in antenna structure provides some attractive features like miniaturization, improved impedance matching, multiband and wideband characteristics. This is due to some significant characteristics of fractal geometry such as self-similarity, non-integer dimension and space filling properties. A crinkle fractal structure-based antenna with partial ground plane [5] and an I-shaped fractal antenna with PSO technique [6] are designed to generate triple band response. PSO technique is used to optimize the length of the I-shaped fractal antenna. A circular ring fractal, meander like fractal and wheel shaped ring fractal with partial ground plane are designed to achieve multiband response with enhancement in bandwidth [7-9]. Enhancement in bandwidth is also achieved in an SRR based hexagonal ring fractal antenna due to slotted ground plane [10]. Another antenna with dual reverse arrow 

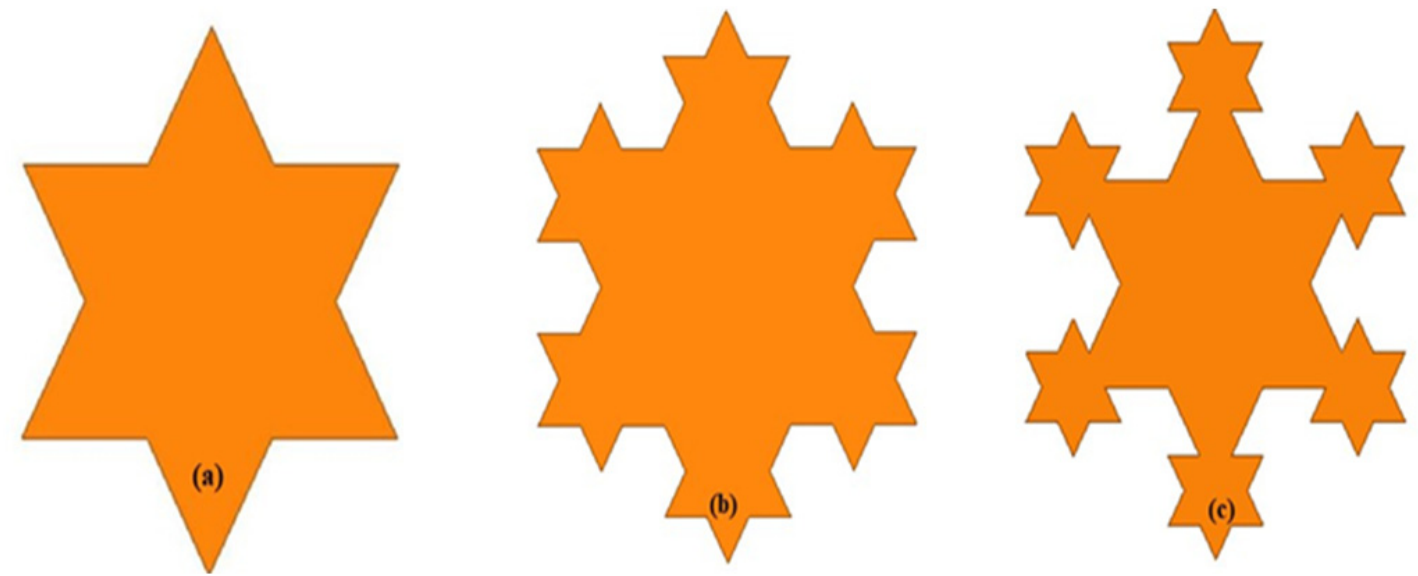

Fig. 1. (a) First iteration Koch loop. (b) Second iteration Koch loop. (c) Modified second iteration Koch loop.

fractal loaded with elevated slot on patch for improvement in bandwidth has been reported in [11]. Design of antennas loaded with different fractal shaped slots such as modified Sierpinski, Koch fractal and $\Psi$-shaped slots to achieve multiband response are described in [12-14]. It has been observed that Koch fractal shaped slot provides more bandwidth in comparison to modified Sierpinski and $\Psi$ shaped slots. A triangular shaped dielectric resonator based Minkowski fractal antenna is designed to achieve wideband response [15]. Besides the Koch fractal, Sierpinski fractal has been also used for monopole antennas for wireless communications [16], [17]. Design of a partial ground plane loaded fractal shaped metasurface antenna is reported in [18]. A periwinkle flower shaped antenna loaded with SRR and fed through modified CPW generated multiband response [19]. Implementation of hybrid fractal technique such as Moore-Koch and Minkowski-Hilbert in antenna geometry with partial ground plane leads to multiband response with wideband behavior [20], [21]. A miniaturized hybrid fractal technique-based antenna generated a narrowband response [22]. A metamaterial antenna loaded with stubs is designed to get multiband response [23]. For bandwidth enhancement the proposed antenna is designed with a slotted partial ground plane.

In this article, a CPW fed antenna using modified Koch fractal geometry-based patch up to second iteration loaded with number of circular slots and partial ground plane is designed and presented. It involves multiple stages of design process and shows that bandwidth improves through every individual stage. Initially, an inset fed truncated star shape is designed and then it is followed by the proposed fractal stage. A multiband response including wideband characteristics, improved reflection coefficient, gain and directional radiation pattern have been obtained in the final stage of the design. In literature most of the antennas with multiband response have not shown wideband behavior in their all-resonating bands whereas the proposed antenna in this context produces wideband behavior in all its resonating bands.

\section{Modified Koch Fractal}

Figure 1(a) shows a star shape which can be equivalent to the $1^{\text {st }}$ iteration Koch loop. Figure 1(b) shows that by adding a star at each corner of the previous star $\left(1^{\text {st }}\right.$ iteration Koch loop) equivalence of $2^{\text {nd }}$ iteration Koch loop can be obtained. In this process center of each corner of the previous star and center of star which is added at each corner are same. In modified second iteration center of each corner of the previous star ( $1^{\text {st }}$ iteration Koch loop) and the center of star which is added at each corner are not same as shown in Fig. 1(c).

\section{Designing Process}

Design and simulation of each stage of the antenna is performed by using HFSS 15. Substrate material for every stage of the antenna design is FR4 epoxy whose dielectric constant and loss tangent are 4.4 and 0.02 respectively. Stage- 1 of the proposed antenna is basically a star shape which is fed directly by using line feeding mechanism as shown in Fig. 2(a). It is considered as the first iteration Koch fractal. In this technique more iterations cause the electrical length $\beta l$ to increase and length of the circumference is given by the mathematical formula $a_{n}=3(4 / 3)^{n}$, where $a_{n}$ is length of the circumference and $n$ is any positive integer. Establishment of proper impedance matching is done by proper adjustment of the feed position and dimension of feedline to achieve increment in bandwidth. For this, a small portion from the basic star shape is removed and hence fed through inset feeding mechanism in stage- 2 as shown in Fig. 2(b). In this mechanism a rectangular notch is made through which a $50 \Omega$ feedline of $\left(W_{\mathrm{f}} \times L_{\mathrm{f}}\right)$ specification is connected to the patch. Parametric analysis is performed to ensure proper feeding point by varying the notch length $\left(L_{\mathrm{n}}\right)$. The design in stage- 2 is a truncated star shape which is obtained by truncating the basic star shape in stage- 1 . So, the stage- 2 is considered as a modification of stage-1 due to truncation rather than due to any iteration. 

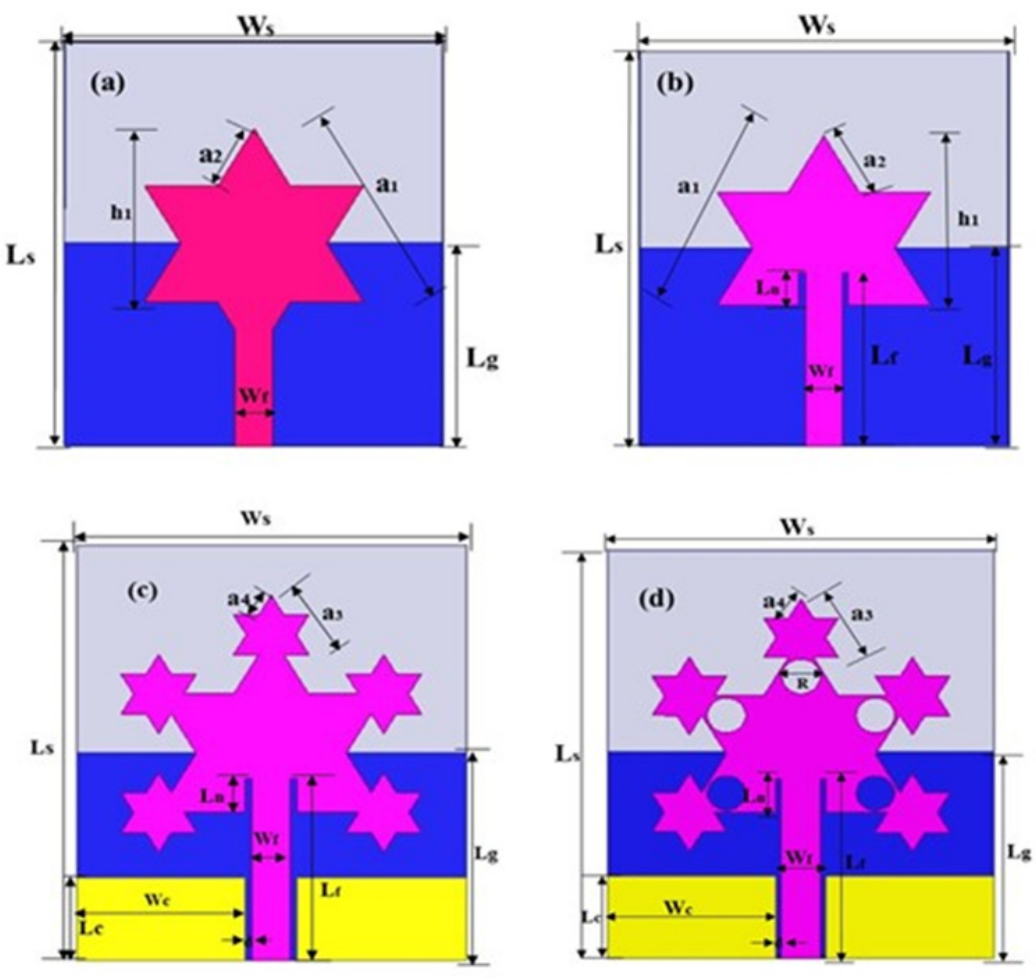

Fig. 2. (a) Stage-1. (b) Stage-2. (c) Stage-3. (d) Stage-4.

\begin{tabular}{|c|c|c|c|c|c|c|c|c|}
\hline $\mathbf{W}_{\mathbf{s}}$ & 30 & $0.6 \lambda_{0}$ & $\mathbf{a}_{\mathbf{2}}$ & 5.77 & $0.116 \lambda_{0}$ & $\mathbf{a}_{\mathbf{4}}$ & 1.92 & $0.039 \lambda_{0}$ \\
\hline $\mathbf{L}_{\mathbf{s}}$ & 35 & $0.7 \lambda_{0}$ & $\mathbf{L}_{\mathbf{n}}$ & 2.9 & $0.058 \lambda_{0}$ & $\mathbf{R}$ & 1.5 & $0.03 \lambda_{0}$ \\
\hline $\mathbf{L}_{\mathbf{g}}$ & 17.5 & $0.35 \lambda_{0}$ & $\mathbf{W}_{\mathbf{f}}$ & 3 & $0.06 \lambda_{0}$ & $\mathbf{d}$ & 0.5 & $0.01 \lambda_{0}$ \\
\hline $\mathbf{h}_{\mathbf{1}}$ & 15 & $0.30 \lambda_{0}$ & $\mathbf{L}_{\mathbf{f}}$ & 15.4 & $0.31 \lambda_{0}$ & $\mathbf{L}_{\mathbf{c}}$ & 7 & $0.14 \lambda_{0}$ \\
\hline $\mathbf{a}_{\mathbf{1}}$ & 17.32 & $0.34 \lambda_{0}$ & $\mathbf{a}_{\mathbf{2}}$ & 5.77 & $0.116 \lambda_{0}$ & $\mathbf{W}_{\mathbf{c}}$ & 13 & $0.26 \lambda_{0}$ \\
\hline
\end{tabular}

Tab. 1. Parametric values of the proposed antenna (All values are in $\mathrm{mm}$ ).

For this, stage-2 still can be considered as the first iteration Koch fractal. In stage-3 design, modified second iteration Koch fractal is implemented by adding a smaller star at each corner of the truncated star shape patch. In this process center of each corner of the truncated star shape patch and center of the smaller star which is added are not same. This is fed through a pair of symmetrical rectangular ground plates which are designed on the top of the substrate through which feedline is connected to the patch; this is known as coplanar waveguide (CPW) feeding as shown in Fig. 2(c). The size of the CPW is optimized by varying the length of CPW $\left(L_{\mathrm{C}}\right)$ while keeping width $\left(W_{\mathrm{C}}\right)$ fixed using parametric analysis. Another parametric analysis is performed to know the appropriate gap $(d)$ between feedline and CPW by keeping length of CPW fixed. Implementation of modified second iteration Koch fractal along with CPW feeding mechanism leads the antenna to produce multiband response. In the final stage of the antenna design, five numbers of circular slots of equal size and shapes are introduced on the CPW fed second iterated patch as shown in Fig. 2(d) to improve the performance of the antenna. Radius of each circle is optimized by per- forming a parametric analysis by considering the radius $(R)$ as a variable. Introduction of circular slots along with partial ground plane improves the bandwidth at each resonating band of the proposed antenna. Table 1 specifies entire dimensions of the antenna structure. For a fractal antenna, the resonance frequency for a given mode can be determined from the following expression.

$$
f_{\mathrm{r}}=\frac{1}{2 a \sqrt{\varepsilon_{\text {reff }}} \sqrt{\mu_{0} \varepsilon_{0}}}
$$

where $f_{\mathrm{r}}$ is the resonance frequency and $a$ is the effective fractal length. Multiple resonance frequencies can be generated by the fractal antenna because fractal supports higher order resonant modes and it leads to occurrence of multiband response.

\section{Parametric Analysis}

This section describes the effect of variations in different parameters to achieve desired response from the proposed antenna. 

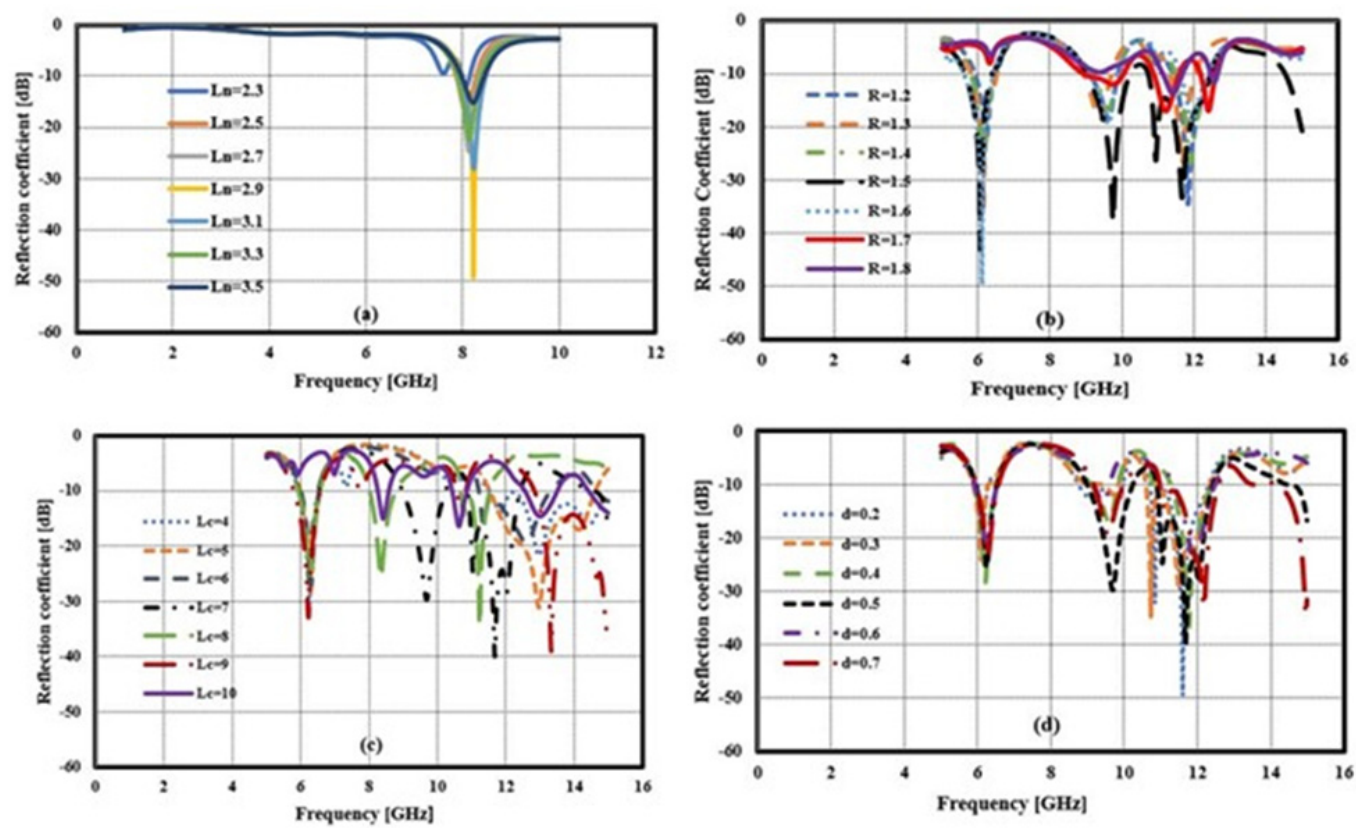

Fig. 3. Parametric variations of: (a) Notch length $L_{\mathrm{n}}$. (b) Radius of circular slots $R$. (c) Length of CPW $L_{\mathrm{c}}$. (d) Gap between CPW and feedline $d$.

\subsection{Variations in Length of the Notch $\left(L_{n}\right)$}

To ensure improvement in impedance matching, a small notch has been made on the truncated star shape patch. Parametric analysis is used to optimize the size of the notch by varying the length $\left(L_{\mathrm{n}}\right)$ is shown in Fig. 3(a). Variation of length is done in the range of 2.3-3.5 $\mathrm{mm}$ with step size of $0.2 \mathrm{~mm}$. It was obtained from simulation that the reflection coefficient is decreased with increasing $L_{\mathrm{n}}$ from $2.3 \mathrm{~mm}$ to $2.9 \mathrm{~mm}$. Beyond $L_{\mathrm{n}}=2.9 \mathrm{~mm}$ reflection coefficient is increased again and minimum reflection coefficient is achieved for $L_{\mathrm{n}}=2.9 \mathrm{~mm}$. At this value, resulted reflection coefficient is of $-49.19 \mathrm{~dB}$ and a bandwidth of $480 \mathrm{MHz}(5.83 \%)$ is obtained, confined within the range of 7.99-8.47 GHz. Beyond this value performance of the proposed antenna is degraded in terms of both bandwidth and reflection coefficient.

\subsection{Variation in Radius of Circular Slots $(R)$}

Five number of circular slots of equal size and shape are loaded on the final stage of the proposed antenna to enhance the performance. To optimize the radius of circles for minimum reflection coefficient and adequate bandwidth, a parametric analysis is performed as shown in Fig. 3(b) by considering radius $R$ as variable. Variation of radius is shown between $1.2-1.8 \mathrm{~mm}$ range in step of $0.1 \mathrm{~mm}$. Here it is shown that it results multiband response with slight variation in bandwidth and reflection coefficient for $R=1.2 \mathrm{~mm}$ to $1.4 \mathrm{~mm}$. At $R=1.5 \mathrm{~mm}$ antenna has attained minimum reflection coefficient and maximum bandwidth. At $R=1.5 \mathrm{~mm}$ it results in multiband response with maximum bandwidth of $1720 \mathrm{MHz}$ in the range of $10.73-12.45 \mathrm{GHz}$ with minimum reflection coefficient of $-33.33 \mathrm{~dB}$. Afterward performance is degraded.

\subsection{Variation in Length of the CPW $\left(L_{C}\right)$}

In order to achieve the desired response, antenna is fed through a pair of CPW ground plates. Gap between $\mathrm{CPW}$ and patch is optimized with variation of CPW length $L_{\mathrm{C}}$ by using parametric analysis as depicted in Fig. 3(c). Variation in length of $\mathrm{CPW}$ is performed between 4-10 $\mathrm{mm}$ in step of $1 \mathrm{~mm}$. It is shown that for $L_{\mathrm{C}}=7 \mathrm{~mm}$ antenna results multiband response with very less amount of reflection coefficient and wideband characteristics is found corresponding to each resonant frequency.

\subsection{Variation of Gap between CPW and Feedline $(d)$}

Figure 3(d) shows the parametric variation of gap $(d)$ between CPW and feedline. Variation of gap is performed between $0.2-0.7 \mathrm{~mm}$ in a step of $0.1 \mathrm{~mm}$. It is shown that for $d=0.5 \mathrm{~mm}$ antenna results multiband response with minimum reflection coefficient and wideband behavior at each resonating band.

\section{Reflection Coefficient and Band- width}

Reflection coefficient and bandwidth of all stages of the antennas are enlightened in this context. Figure 4(a) shows the variation of reflection coefficient of all design stages. Comparison of reflection coefficient plot between measured and simulated data of the antenna in final stage is shown in Fig. 4(b). Initially, a basic direct fed star shape patch is formed and simulated which resonates at $7.70 \mathrm{GHz}$ with reflection coefficient $-18.70 \mathrm{~dB}$ and results a narrow- 

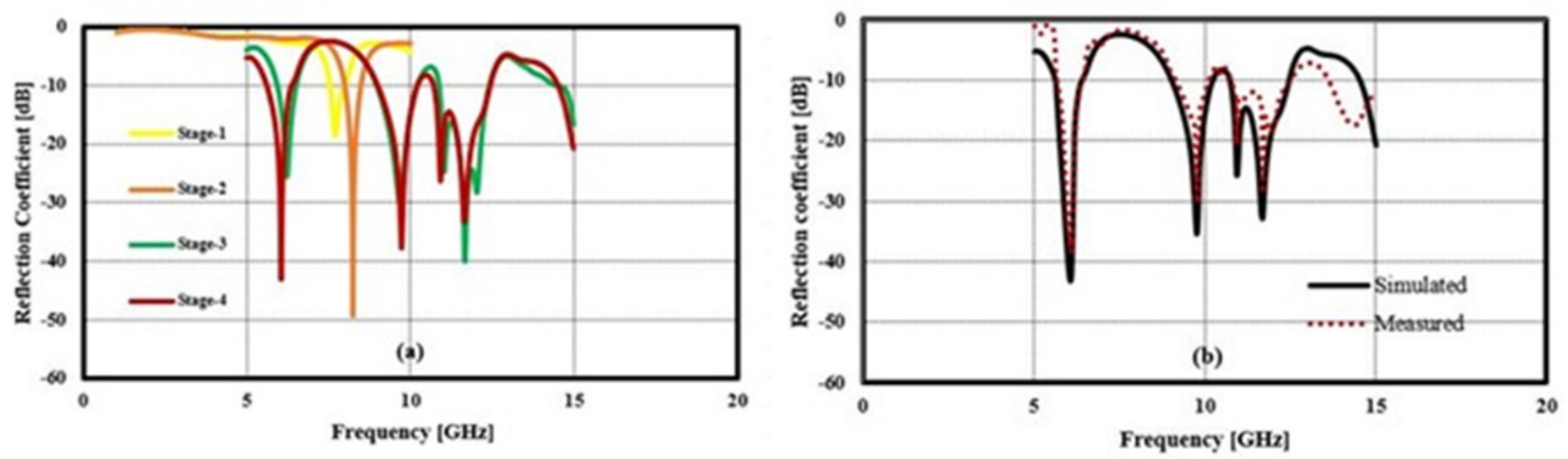

Fig. 4. (a) Simulated reflection coefficient variations of all stages. (b) Comparison of reflection coefficient between measured and simulated data of the proposed antenna.
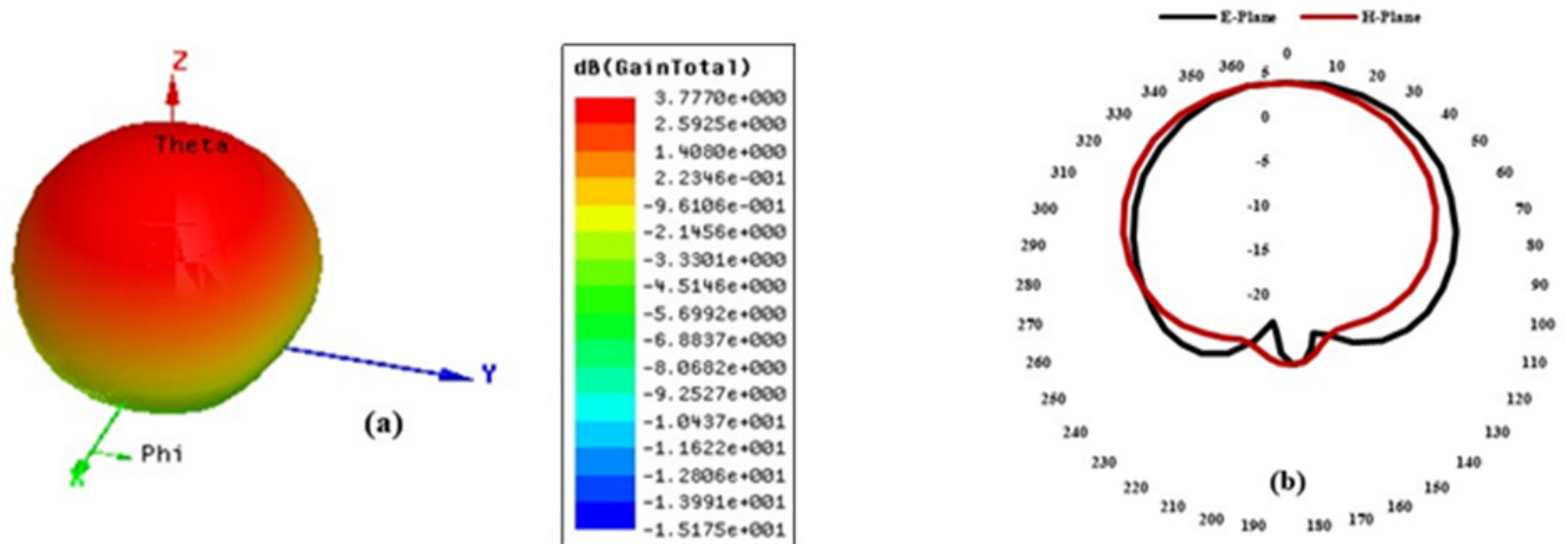

Fig. 5. (a) $3 \mathrm{D}$ far field pattern with peak gain. (b) E-plane and H-plane radiation patterns of the truncated star shape patch at $8.23 \mathrm{GHz}$.

band response. In order to get improved impedance matching and better bandwidth, star shape is truncated in stage-2. Because of the truncation electrical length of the patch decreases which leads to increase of resonant frequency. Here antenna results in a resonant frequency of $8.23 \mathrm{GHz}$ with reflection coefficient $-49.19 \mathrm{~dB}$ and bandwidth $480 \mathrm{MHz}(5.83 \%)$ within the range $7.99-8.47 \mathrm{GHz}$. Truncated star shape patch results in an increase in resonant frequency due to the length reduction by truncation. Additionally, it offers improvement in impedance matching and bandwidth. For further improvement of the antenna performance, stage- 2 is gone through a process of modified Koch iteration in stage- 3 known as second iteration. The CPW fed second iterated modified Koch fractal antenna in stage-3, generates multiband response. This shows the simulated reflection coefficients of $-25.35 \mathrm{~dB},-29.35 \mathrm{~dB}$, $-24.55 \mathrm{~dB}$, and $-39.64 \mathrm{~dB}$ at resonant frequencies $6.24 \mathrm{GHz}, 9.67 \mathrm{GHz}, 11.03 \mathrm{GHz}$ and $11.67 \mathrm{GHz}$ respectively. The offered bandwidth at all resonating bands are given as $560 \mathrm{MHz}(9.03 \%)(5.92-6.48 \mathrm{GHz}), 1260 \mathrm{MHz}$ $(13.12 \%) \quad(8.97-10.23 \mathrm{GHz})$ and $1500 \mathrm{MHz}(12.89 \%)$ $(10.88-12.38 \mathrm{GHz})$. It is observed that second iteration results in a decrease in resonant frequency and produces additional resonating bands. Circular slots loaded in the final design stage of the antenna improve the performance in terms of reflection coefficients, bandwidth and gain. Loading of circular slots in the final stage is also responsi- ble to operate the antenna within the desired bands. It is also responsible to improve the reflection coefficients at each of the resonating bands. The final design of the proposed antenna shows simulated reflection coefficients of $-43.17 \mathrm{~dB},-37.85 \mathrm{~dB},-26.34 \mathrm{~dB}$ and $-33.33 \mathrm{~dB}$ at frequencies $6.06 \mathrm{GHz}, 9.74 \mathrm{GHz}, 10.93 \mathrm{GHz}$ and $11.67 \mathrm{GHz}$ respectively. The offered bandwidth at all resonating bands is given as $770 \mathrm{MHz} \quad(12.82 \%) \quad(5.62-6.39 \mathrm{GHz})$, $1190 \mathrm{MHz}(12.38 \%)(9.01-10.20 \mathrm{GHz})$ and $1720 \mathrm{MHz}$ (14.84\%) (10.73-12.45 GHz). Therefore, the antenna offers multiband response with improved bandwidth in all operating bands in this stage. The final design of the proposed antenna shows measured reflection coefficients of $-38.34 \mathrm{~dB}$, $-30.25 \mathrm{~dB},-20.58 \mathrm{~dB},-28.69 \mathrm{~dB}$ and $-17.32 \mathrm{~dB}$ at resonant frequencies $6.06 \mathrm{GHz}, 9.76 \mathrm{GHz}, 10.92 \mathrm{GHz}$, $11.68 \mathrm{GHz}$ and $14.4 \mathrm{GHz}$ respectively. The offered bandwidth at all resonating bands is given as $510 \mathrm{MHz}(8.42 \%)$ $(5.8-6.31 \mathrm{GHz}), \quad 880 \mathrm{MHz} \quad(9.12 \%) \quad(9.2-10.08 \mathrm{MHz})$, $1580 \mathrm{MHz}(13.65 \%)(10.78-12.36 \mathrm{GHz})$ and $1360 \mathrm{MHz}$ (9.49\%) (13.64-15 GHz).

\section{Far Field Results}

Gain and radiation patterns obtained from all the design stages are enlightened in this discussion. Figure 5(a) shows the $3 \mathrm{D}$ polar plot of truncated star shape patch 
(Stage-2) with a peak gain of $3.77 \mathrm{~dB}$ at $8.23 \mathrm{GHz}$. Figure 5(b) shows both the electric and magnetic field planes $2 \mathrm{D}$ radiation patterns. It has been seen that both $\mathrm{E}$ and $\mathrm{H}-$ plane have produced omnidirectional field patterns for the given frequency.

Stage- 3 that is the modified second iterated patch produces peak gains of $1.5 \mathrm{~dB}, 5.13 \mathrm{~dB}, 1.82 \mathrm{~dB}$ and $2.44 \mathrm{~dB}$ corresponding to resonant frequencies $6.24 \mathrm{GHz}$, $9.67 \mathrm{GHz}, \quad 11.03 \mathrm{GHz}$ and $11.67 \mathrm{GHz}$ respectively as shown in Fig. 6. Stage-4 that is the final design of the pro- posed antenna produces peak gains of $3.99 \mathrm{~dB}, 7.98 \mathrm{~dB}$, $4.8 \mathrm{~dB}$ and $3.96 \mathrm{~dB}$ corresponding to resonant frequencies $6.06 \mathrm{GHz}, 9.74 \mathrm{GHz}, 10.93 \mathrm{GHz}$ and $11.67 \mathrm{GHz}$ respectively as shown in Fig. 7. Radiation patterns of the modified second iterated patch for both $\mathrm{E}$ and $\mathrm{H}$ planes are shown in Fig. 8. It has been observed that the proposed antenna produces almost omnidirectional E-plane pattern for the frequency $9.67 \mathrm{GHz}$ and directional E-plane pattern for $6.24 \mathrm{GHz}$. It produces directional E-plane patterns with minor side lobes for the frequencies 11.03 and $11.67 \mathrm{GHz}$.

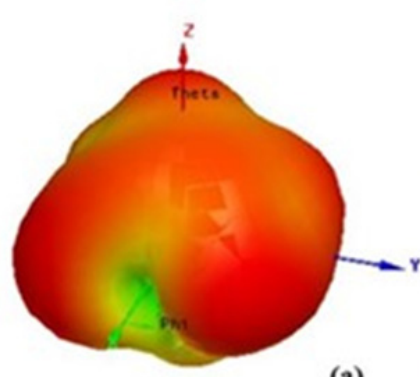

(a)
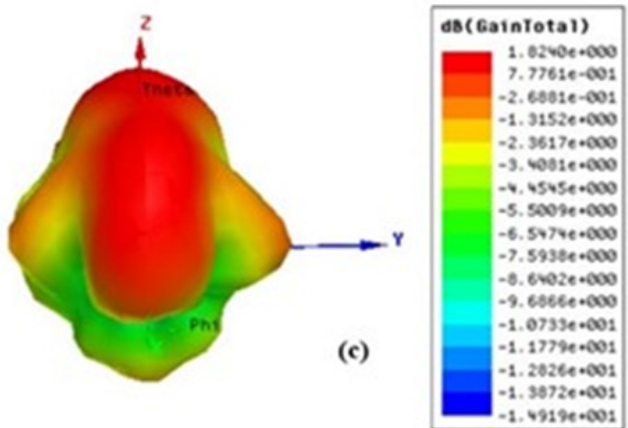

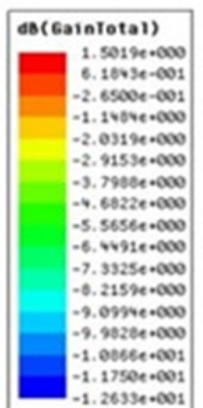

$1.2633 e \cdot 001$
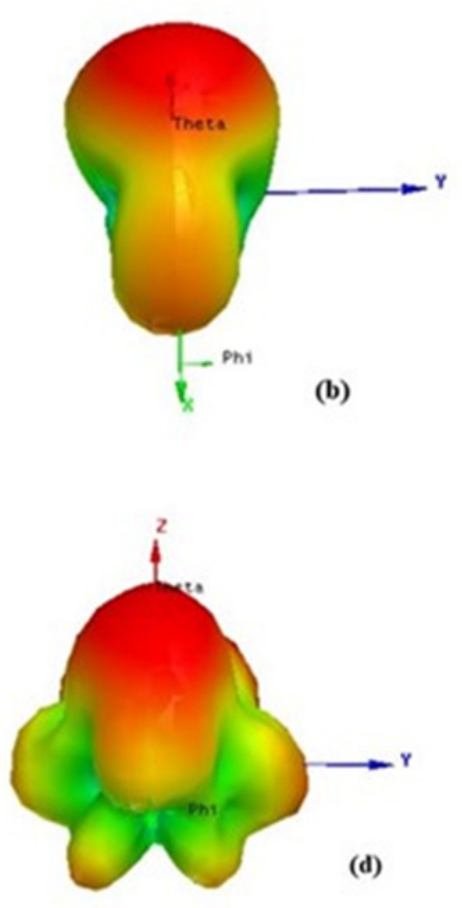
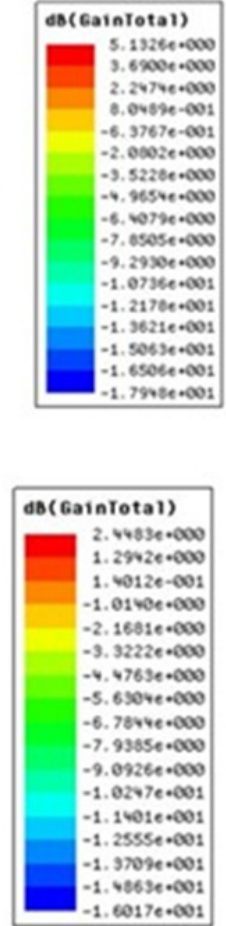

Fig. 6. 3D far field pattern of modified $2^{\text {nd }}$ iterated patch with peak gain at (a) $6.24 \mathrm{GHz}$, (b) $9.67 \mathrm{GHz}$, (c) $11.03 \mathrm{GHz}$, (d) $11.67 \mathrm{GHz}$.
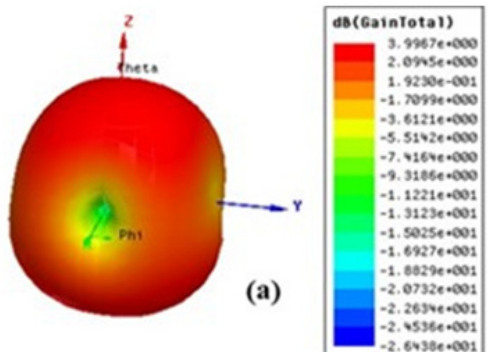

$.64306 \cdot 001$

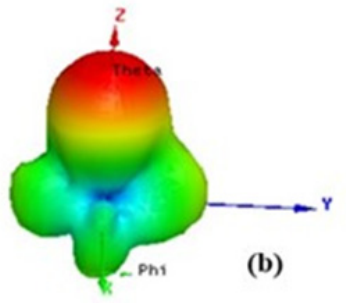

(b)
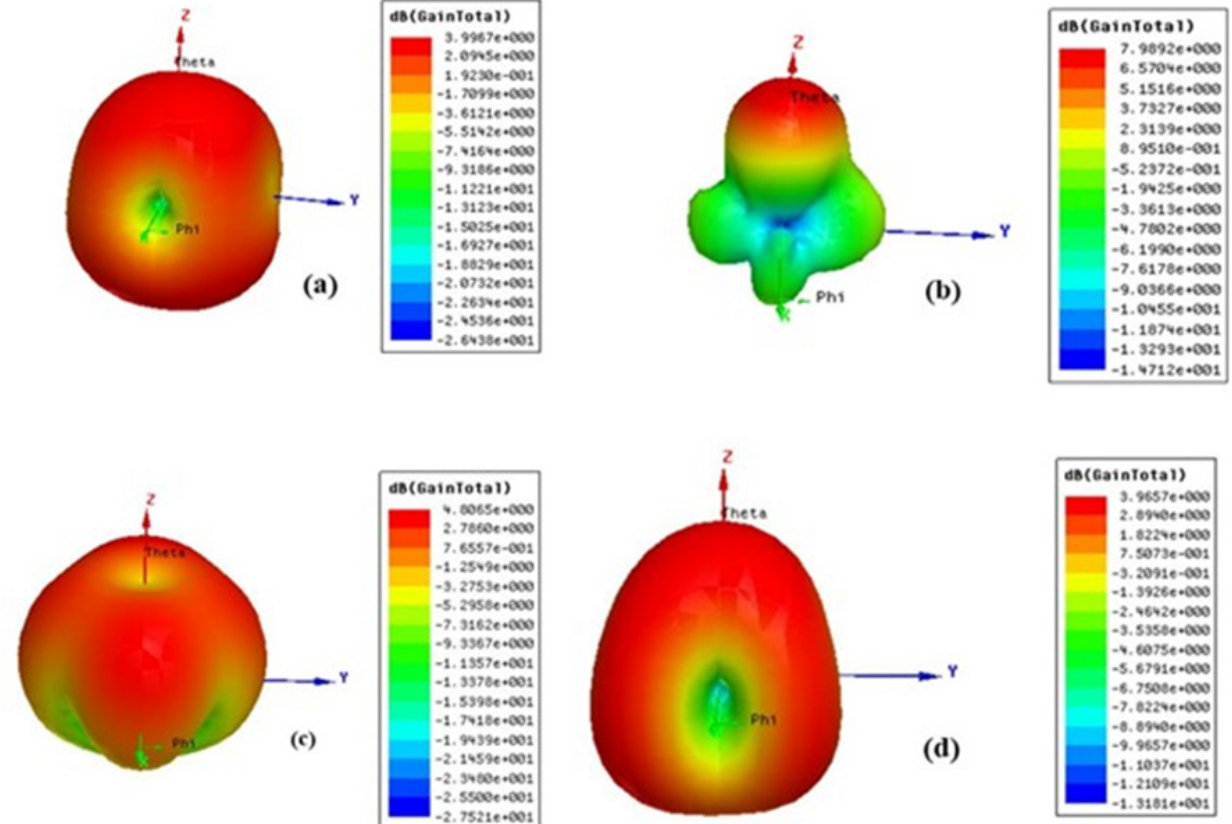

Fig. 7. 3D far field pattern of the final design stage of the proposed antenna with peak gain at (a) $6.06 \mathrm{GHz}$, (b) $9.74 \mathrm{GHz}$, (c) $10.93 \mathrm{GHz}$, (d) $11.67 \mathrm{GHz}$. 


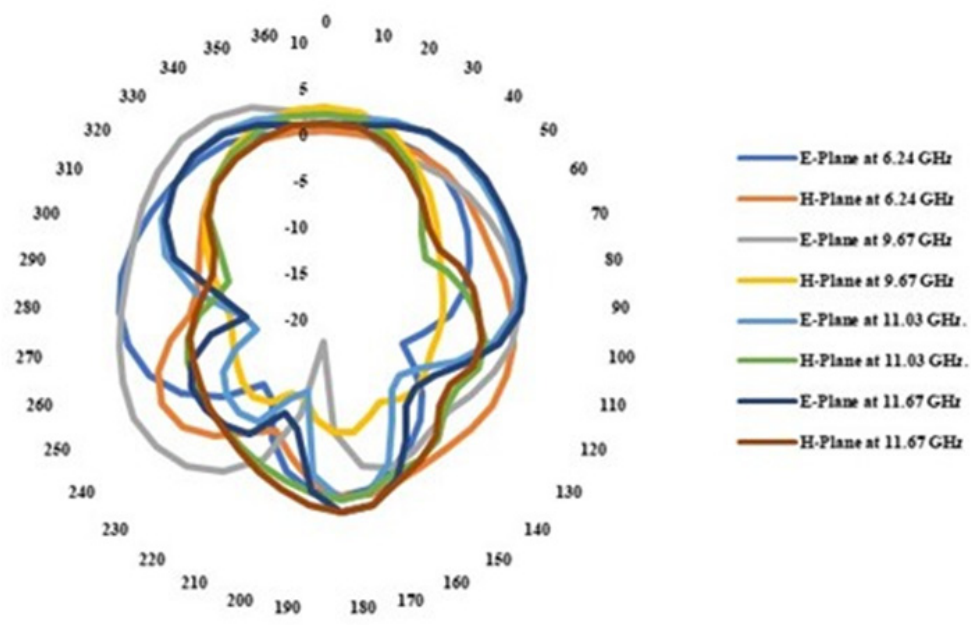

Fig. 8. E-plane and H-plane patterns of the modified second iterated patch.

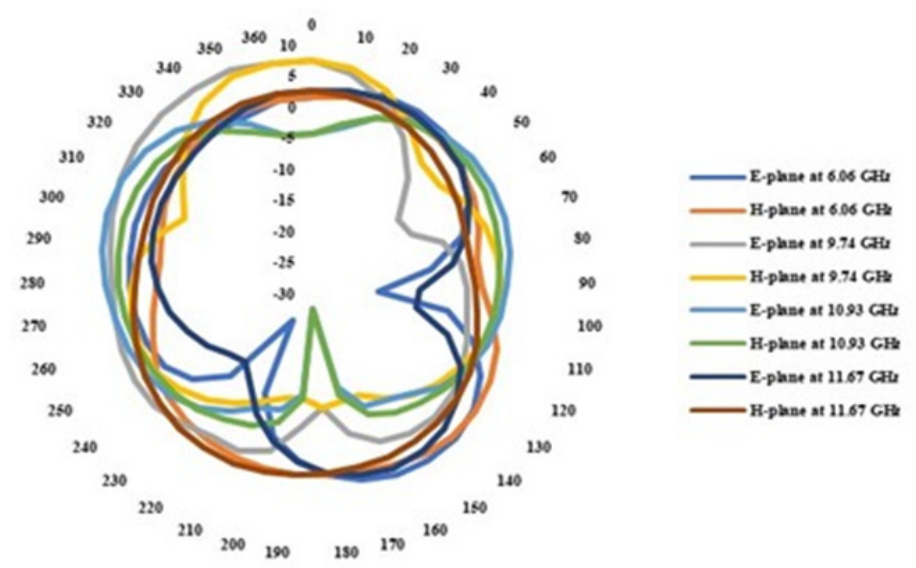

Fig. 9. E-plane and H-plane patterns of the final stage of the proposed antenna.
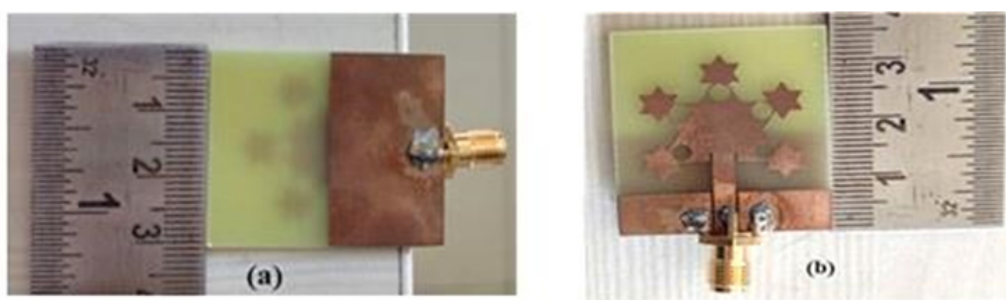

Fig. 10. Fabrication prototype: (a) Back side. (b) Front side.

\begin{tabular}{|c|c|c|c|c|}
\hline Design stages & No. of bands & Resonant frequency $\mathbf{( G H z )}$ & Reflection coefficient (dB) & Bandwidth $(\mathbf{M H z})$ \\
\hline $\begin{array}{c}\text { Stage-2 (1st iteration) } \\
\text { (Truncated star shape) }\end{array}$ & 1 & 8.23 & -49.19 & $480(5.83 \%)$ \\
\hline $\begin{array}{c}\text { Stage-3 (Modified 2nd } \\
\text { iterated patch) }\end{array}$ & 4 & $6.24,9.67,11.03,11.67$ & $-25.35,-29.35,-24.55$, & $\begin{array}{c}560(9.03 \%), 1260 \\
(13.12 \%), 1500(12.89 \%), \\
1500(12.89 \%)\end{array}$ \\
\hline Stage-4 (Final) Simulated & 4 & $6.06,9.74,10.93,11.67$ & $-43.17,-37.85,-26.34$, & $\begin{array}{c}770(12.82 \%), 1190 \\
(12.38 \%), 1720(14.84 \%), \\
1720(14.84 \%)\end{array}$ \\
\hline Stage-4 (Final) Measured & 5 & $6.06,9.76,10.92,11.68,14.4$ & $-38.34,-30.25,-20.58$, & $\begin{array}{c}510(8.42 \%), 880(9.12 \%), \\
1580(13.65 \%), 1580 \\
(13.65 \%), 1360(9.49 \%)\end{array}$ \\
\hline
\end{tabular}

Tab. 2. Parametric outcomes from various design steps of the proposed antenna. 


\begin{tabular}{|c|c|c|c|c|}
\hline Design stages & No. of bands & Resonant frequency $\mathbf{( G H z )}$ & Peak gain (dB) & Radiation efficiency (\%) \\
\hline $\begin{array}{c}\text { Stage-2 }\left(1^{\text {st }} \text { iteration) }\right. \\
\text { (Truncated star shape) }\end{array}$ & 1 & 8.23 & 3.77 & 94.53 \\
\hline $\begin{array}{c}\text { Stage-3 (Modified } 2^{\text {nd }} \\
\text { iterated patch) }\end{array}$ & 4 & $6.24,9.67,11.03,11.67$ & $1.5,5.13,1.82,2.44$ & $82.38,78.14,53.77,78.40$ \\
\hline Stage-4 (Final) & 4 & $6.06,9.74,10.93,11.67$ & $3.99,7.98,4.8,3.96$ & $86.54,77.7,58,80$ \\
\hline
\end{tabular}

Tab. 3. Gain and radiation efficiencies from various design steps of the proposed antenna.

\begin{tabular}{|c|c|c|c|c|c|}
\hline References & Antenna size (mm $\mathbf{( m}^{\mathbf{2}}$ & $\begin{array}{c}\text { Nature of the } \\
\text { antenna }\end{array}$ & $\begin{array}{c}\text { Maximum } \\
\text { bandwidth (MHz) }\end{array}$ & $\begin{array}{c}\text { Minimum } \\
\text { bandwidth (MHz) }\end{array}$ & Feeding mechanism \\
\hline$[1]$ & $2.745 \lambda_{0} \times 1.7 \lambda_{0}$ & Multiband & $400(7.09 \%)$ & $100(1.67 \%)$ & Line \\
\hline$[2]$ & $0.276 \lambda_{0} \times 0.409 \lambda_{0}$ & Triple band & $330(4.45 \%)$ & $200(6.06 \%)$ & Line \\
\hline$[5]$ & $0.083 \lambda_{0} \times 0.083 \lambda_{0}$ & Triple band & $302(5.7 \%)$ & $189(10.58 \%)$ & Line \\
\hline$[6]$ & $0.5 \lambda_{0} \times 0.33 \lambda_{0}$ & Triple band & $510(6.99 \%)$ & $75(1.27 \%)$ & Line \\
\hline$[7]$ & $0.79 \lambda_{0} \times 0.46 \lambda_{0}$ & Multiband & $860(15.6 \%)$ & $190(6.89 \%)$ & Line \\
\hline$[10]$ & $0.299 \lambda_{0} \times 0.438 \lambda_{0}$ & Triple band & $860(15.99 \%)$ & $290(11.49 \%)$ & Line \\
\hline$[11]$ & $0.29 \lambda_{0} \times 0.208 \lambda_{0}$ & Dual band & $1000(18.51 \%)$ & $100(3.48 \%)$ & Coaxial \\
\hline$[13]$ & $0.57 \lambda_{0} \times 0.57 \lambda_{0}$ & Dual band & $1060(21.15 \%)$ & $690(26.69 \%)$ & Line \\
\hline$[14]$ & $0.268 \lambda_{0} \times 0.321 \lambda_{0}$ & Multiband & So narrow & So narrow & Coaxial \\
\hline$[15]$ & $0.85 \lambda_{0} \times 0.85 \lambda_{0}$ & Single band & $870(32.64 \%)$ & - & Coaxial \\
\hline$[18]$ & $0.43 \lambda_{0} \times 0.43 \lambda_{0}$ & Single band & $200(4.08 \%)$ & Line \\
\hline$[19]$ & $0.16 \lambda_{0} \times 0.16 \lambda_{0}$ & Multiband & So narrow & So narrow & CPW fed \\
\hline Proposed design & $\mathbf{0 . 7} \lambda_{\mathbf{0}} \times \mathbf{0 . 6} \boldsymbol{\lambda}_{\mathbf{0}}$ & Multiband & $\mathbf{1 5 8 0}(\mathbf{1 3 . 6 5 \% )}$ & $\mathbf{5 1 0 ( 8 . 4 2 \% )}$ & CPW fed \\
\hline
\end{tabular}

Tab. 4. Comparison of the proposed antenna with various existing multiband antennas.

It is seen that H-plane patterns produced by the antenna are highly directional for all the resonant frequencies. Radiation patterns of the antenna in final stage for both $\mathrm{E}$ and $\mathrm{H}$ planes are shown in Fig. 9. It is observed that the antenna produces bidirectional E-plane patterns for the frequencies $6.06 \mathrm{GHz}, 10.93 \mathrm{GHz}$ and $11.67 \mathrm{GHz}$. At frequency $9.74 \mathrm{GHz}$, both $\mathrm{E}$ and $\mathrm{H}$ plane patterns are highly directional. The antenna produces almost omnidirectional patterns at frequencies $6.06 \mathrm{GHz}$ and $11.67 \mathrm{GHz}$ whereas at $10.93 \mathrm{GHz}$ it produces bidirectional $\mathrm{H}$-plane pattern. It has been seen that introduction of circular slots in the final stage of the proposed antenna enhances the magnitude as well as the pattern of gain over each resonating band.

Table 2 shows both the measured and simulated bandwidth and reflection coefficients of the final stage of the antenna with their corresponding resonant frequencies. It also shows the summarized parametric outcomes of the different design stages of the antenna. Table 3 contains the far field outcomes including peak gains and radiation efficiencies of all design stages of the antenna. Table 4 finds a comparison between various existing antennas with different structures and feeding techniques offering multiband response. It has been observed that the proposed antenna provides multiband response with wideband behavior at all the resonating bands. The maximum and minimum bandwidths produced by the antenna are of $1580 \mathrm{MHz}$ and $510 \mathrm{MHz}$ respectively.

\section{Conclusion}

A modified Koch fractal-based patch antenna up to second iteration loaded with number of circular slots of equal size and shape fed with CPW technique is designed and tested in this article. The antenna is designed through a number of stages, including a continuous improvement of the parametric performance. Wideband is obtained due to introduction of partial ground and circular slots on the antenna. A multiband response with wideband characteristics is obtained due to introduction of modified Koch fractal with CPW feeding. Introduction of circular slots is also responsible to enhance the gain and improve the reflection coefficient at each of the resonating band. The simulated outcomes of the antenna have been plotted graphically against the measured set of data. A very good match has been observed between the simulated and measured results. The proposed antenna can be a good choice for different fields of wireless communication such as Fixed Satellite for earth to space $(5.850-5.925 \mathrm{GHz})$, Amateur Satellite for space to earth $(5.83-5.85 \mathrm{GHz})$, Radar $(9.5-10.05 \mathrm{GHz})$ and DBS TV (11.7-12.3 GHz) applications. 


\section{References}

[1] KAUSHAL, D., SHANMUGANANTHAM, T. A Vinayak slotted rectangular microstrip patch antenna design for C-band applications. Microwave and Optical Technology Letters, 2017, vol. 59 , no. 8 , p. 1833-1837. DOI: 10. 1002/mop.30628

[2] BADR, S., B., HAMAD, E. K. I. Design of multiband microstrip patch antenna for WiMax, C-band and X-band applications. Aswan Engineering Journal (AswEJ), 2018, p. 1-7.

[3] TAGHIZADEH, H., GHOBADI, CH., AZARM, B., et al. Grounded coplanar waveguide-fed compact MIMO antenna for wireless portable applications. Radioengineering, 2019, vol. 28, no. 3 , p. 528-534. DOI: $10.13164 /$ re.2019.0528

[4] ACHARJEE, J., SINGH, A. K., MANDAL, K., et al. Defected ground structure toward cross polarization reduction of microstrip patch antenna with improved impedance matching. Radioengineering, 2019, vol. 28, no. 1, p. 33-38. DOI: $10.13164 /$ re. 2019.0033

[5] BEIGI, P., MOHAMMADI, P. A novel small triple-band monopole antenna with crinkle fractal-structure. $A E U$ International Journal of Electronics and Communications, 2016, vol. 70, no. 10, p. 1382-1387. DOI: 10.1016/j.aeue.2016.07.013

[6] KAKKAR, S., KAMAL, T. S., SINGH, A. P. On the design and analysis of I-shaped fractal antenna for emergency management. IETE Journal of Research, 2019, vol. 65, no. 1, p. 104-113. DOI: 10.1080/03772063.2017.1407270

[7] KRISHNA, CH. M., VARMA, P. K., VIJAY, J. P. Bandwidth enhancement of circular ring fractal antenna for wireless applications. In Panda, G., Satapathy, S., Biswal, B., et al. (eds.) Microelectronics, Electromagnetics and Telecommunications. Lecture Notes in Electrical Engineering, 2019, vol. 521, p. 299 to 309. DOI: 10.1007/978-981-13-1906-8_31

[8] BHATIA, S. S., SIVIA, J. S., SHARMA, N. An optimal design of fractal antenna with modified ground structure for wideband applications. Wireless Personal Communication, 2018, vol. 103, p. 1977-1991. DOI: 10.1007/s11277-018-5891-2

[9] GUPTA, M., MATHUR, V. Wheel shaped modified fractal antenna realization for wireless communications. $A E U$ International Journal of Electronics and Communications, 2017, vol. 79, p. 257-266. DOI: 10.1016/j.aeue.2017.06.017

[10] SARASWAT, R. K., KUMAR, M. Implementation of metamaterial loading to miniaturized UWB dipole antenna for WLAN and WiMAX applications with tunability characteristics. IETE Journal of Research, 2019, p. 1-14. DOI: 10.1080/03772063.2019.1684845

[11] SOLEIMANI, H., ORAIZI, H. Miniaturization and dual-banding of an elevated slotted patch antenna using the novel dual-reversearrow fractal. International Journal of $R F$ and Microwave Computer Aided Engineering, 2017, vol. 27, no. 5, p. 1-9. DOI: $10.1002 /$ mmce. 21085

[12] DEVESH, T., ANSARI, J. A., SIDDIQUI, M. G., et al. Analysis of modified square Sierpinski gasket fractal microstrip antenna for wireless communications. AEU-International Journal of Electronics and Communications, 2018, vol. 94, p. 377-385. DOI: 10.1016/j.aeue.2018.07.027

[13] YASSEN, M. T., HUSSAN, M. R., HAMMAS, H. A., et al. A dual-band printed antenna design based on annular Koch snowflake slot structure. Wireless Personal Communications, 2018, vol. 104, p. 649-662. DOI: 10.1007/s11277-018-6039-0

[14] KAUR, G., RATTAN, M., JAIN, C. Design and optimization of psi ( $\Psi)$ slotted fractal antenna using ANN and GA for multiband applications. Wireless Personal Communication, 2017, vol. 97, p. 4573-4585. DOI 10.1007/s11277-017-4739-5
[15] SUR, D., SHARMA, A., GANGWAR, R. K., et al. A novel wideband Minkowski fractal antenna with assistance of triangular dielectric resonator elements. International Journal of $R F$ and Microwave Computer Aided Engineering, 2018, vol. 29, no. 2, p. 1-8. DOI: $10.1002 /$ mmce. 21524

[16] ANGUERA, J., DANIEL, J. P., BORJA, C., et al. Metallized foams for antenna design: Application to fractal-shaped Sierpinskicarpet monopole. Progress In Electromagnetics Research PIER, 2010, vol. 104, p. 239-251. DOI: 10.2528/PIER10032003

[17] ANGUERA, J., ANDUJAR, A., JAYASINGHE, J., et al. Fractal antennas: An historic perspective. Fractal and Fractional, 2020, vol. 4, no. 1, p. 1-26. DOI: 10.3390 /fractalfract 4010003

[18] IYAMPALAM, P., GANESAN, I. Low profile antenna based on a fractal shaped metasurface for public safety applications. International Journal of $R F$ and Microwave Computer Aided Engineering, 2019, vol. 30, no. 2, p. 1-12. DOI: $10.1002 /$ mmce. 22048

[19] ELAVARASI, C., SHANMUGANANTHAM, T. SRR loaded periwinkle flower-shaped fractal antenna for multiband applications. Microwave and Optical Technology Letters, 2017, vol. 59 , no. 10, p. 2518-2525. DOI: 10.1002/mop.30763

[20] SHARMA, N., BHATIA, S. S. Split ring resonator based multiband hybrid fractal antennas for wireless applications. $A E U$ International Journal of Electronics and Communications, 2018, vol. 93, p. 39-52. DOI: 10.1016/j.aeue.2018.05.035

[21] BANGI, I. S., SIVIA, J. S., Minkowski and Hilbert curves based hybrid fractal antenna for wireless applications. International Journal of Electronics and Communications, 2018, vol. 85, p. 159-168. DOI: 10.1016/j.aeue.2018.01.005

[22] RAO, N., DINESH KUMAR, V. Miniaturization of microstrip patch antenna for satellite communication: A novel fractal geometry approach. Wireless Personal Communication, 2017, vol. 97, p. 3673-3683. DOI 10.1007/s11277-017-4691-4

[23] SONAK, R., AMEEN, M., CHAUDARY, R. K. Triple band omnidirectional miniaturized metamaterial inspired antenna using flipped rectangular stub for LTE, WiMAX, and WLAN applications. International Journal of $R F$ and Microwave Computer Aided Engineering, 2019, vol. 29, no. 7, p. 1-9. DOI: 10.1002/mmce. 21721

\section{About the Authors...}

Rajib Kumar DASH is currently working as a research scholar in the National Institute of Technology, Agartala, India. He completed his M.Tech in Communication Engineering from Biju Patnaik University of Technology (BPUT), Odisha, India in 2015. His primary research interest mainly contains design of fractal-based multiband and wideband antennas, antenna design based upon metamaterial, wearable antennas and so on. He has more than ten years of teaching experience.

Puspendu Bikash SAHA completed his M.Tech from the National Institute of Technology, Agartala, India in Communication Engineering in 2015. Presently, he is continuing as a Ph.D. scholar in the same institution. His major research topics include design of MIMO antennas, reconfigurable wideband antennas, application of microwave circuits and so on. He has produced more than three years of teaching experience. 
Dr. Dibyendu GHOSHAL has published more than 160 research articles. His major area of research interest includes millimeter wave application, design of microwave circuits, multiband microstrip patch antennas, optical communication and so on. He also has produced more than twelve years of teaching experience. He completed his Ph.D. (Tech) in 1997 from the Institute of Radio Physics and Electronics, Calcutta University, Calcutta, India. Presently, he is working as an Associate Professor in the National Institute of Technology, Agartala, India.
Dr. Gopinath PALAI is presently working as a Professor in the Department of Electronics and Communication Engineering at Gandhi Institute for Technological Advancement (GITA), Bhubaneswar, India. His major research fields contain optical communication, design of circuits for microwave application, application of electromagnetic wave and so on. He has produced more than 180 research articles in various reputed journals all over the world. $\mathrm{He}$ has completed his Ph.D. degree from the Indian Institute of Technology, Kharagpur, India in Electronics Engineering. 